\title{
NGOs, Participatory Development and Construction of Identities: Involving Men in Gender and Development (GAD) Programs in South
}

\author{
Asia \\ Aamir Jamal $^{1}$ \\ ${ }^{1}$ Assistant Professor, St. Thomas University, Fredericton, New Brunswick \\ Correspondence: Dr. Aamir Jamal, School of Social Work, St. Thomas University, Fredericton, New Brunswick, \\ Canada
}

Received: February 14, 2014 Accepted: February 26, 2014 Online Published: March 16, 2014

doi:10.5430/wjss.v1n2p1 URL: http://dx.doi.org/10.5430/wjss.v1n2p1

\begin{abstract}
This article is a critical examination of development discourse, focusing on the process by which identities are constructed in the interactions between NGO workers and communities. Through an examination of gender and development (GAD) programs in South Asia, I explore some of the challenges and contradictions that arise in participatory development. I argue that sustainable practice can be achieved only through self-reflective, inclusive, and respectful relationships. Review of GAD initiatives in the Pashtun region of Pakistan and Afghanistan leads to the realization that there is urgent need to constructively engage men in gender-related programs.
\end{abstract}

Keywords: NGOs, Participatory Approach, Gender and Development, South Asia, Pakistan, Afghanistan

\section{Introduction}

The remarkable proliferation in the number and size of non-governmental organizations (NGOs) in developing countries, together with the constant rise in funding from Western donors, has made them powerful actors in global politics and international development. In Pakistan, the number of registered NGOs is estimated to be more than 100,000 (Naviwala 2010). However, people in developing countries often perceive NGOs with suspicion due to the increased political involvement and military interventions of the Western world in the region. The public perception of NGOs is diverse and often contradictory. In her important study based on three hundred interviews with respondents across Pakistan, Bano (2008) found that NGOs are often perceived as solely dependent on foreign development aid and as lacking in public legitimacy. High monetary compensation of NGO leaders, along with well-publicized scandals, has fuelled criticism of the sector (Laumann 2000; Bano 2008). Many studies have raised questions about NGOs' claim of participatory development and their impact on the communities they seek to help. The criticism is made that instead of engaging communities and listening to their voices, NGOs are creating-in urban areas, at least - a new elite class, immersed in Western values and disconnected from their communities (Bano 2008; Henderson 2002; Shehabuddin 2000).

This article critically examines development discourse, with particular attention to the process by which identities are constructed in the relationships between NGO workers and the target community. I begin by exploring development discourses and the construction of identities. Next I describe the historical progress in gender and development (GAD) and participatory approaches. Through an examination of GAD programs in South Asia, especially the Pashtun region of northwest Pakistan and Afghanistan, I then consider some of the challenges and contradictions that often arise in practice. I argue that an effective and transparent development practice holds constructive possibilities that can be achieved through attitudes that are culturally sensitive, inclusive, honest, and open. I conclude by arguing that men need to be involved in GAD discourse, particularly in initiatives involving the highly patriarchal communities of northwest Pakistan and Afghanistan.

\section{Development Discourse and Construction of Identities}

In the context of development aid, discourse can be defined as a "historically, socially and institutionally specific 
structure of representations or articulations through which meanings are constructed and social practices organised" (Baaz 2005, 11). Laclau and Mouffe (2001) state that the term discourse suggests that every social configuration has a meaning attached to it. Discourses, however, are not closed or complete systems but open-ended and continuously linked to and influenced by other discourses. A discourse may be understood as a "temporary closure" of an articulated meaning, which could reduce or exclude other possible meanings. Identities are thus temporary attachments to the subject positions that discursive practices construct for us. For example, in her research on the identities of Swedish and Danish development workers in Tanzania, Eriksson Baaz (2005) makes an important contribution when she connects development literature with postcolonial literature. Discussing the complexities in relationships between development aid and the politics of identities, Baaz points to the emergence of paternalism-typical of colonialism - in the identities of development workers in the era of participatory development. Her interviews expose significant tensions between the development claims of partnership and the existing practice; her work underscores the problematic links between colonialist tendencies in development discourse and the formation of worker identities.

In development practice, donor and development worker together present a specific identity that keeps them in a power relationship vis-à-vis their recipients. This positioning of identities defines "others" as inferior and passive. The negativity of "others" in postcolonial discourse does not merely include issues of poor communication, skills, and technology, but also poor moral values, poor education - in short, overall cultural backwardness. As Baaz (2005) argues, even in the partnership discourse the "other" partner is considered unreliable and untrustworthy compared to Westerners. The "underdeveloped" are construed as ignorant and uncivilized and thus in need of the continuous presence of Western NGOs. If a project does not achieve its objective, the blame is placed on the local community's lack of knowledge and skills (Bradley 2006).

The analysis of discourse is simultaneously an analysis of power. As mentioned, discourse constructs desired meanings by excluding and restricting certain forms of speech and thought. Discourse uses power to shape the production of knowledge (Thomsson 2006). Power, according to Foucault (1980), "traverses and produces things, it induces pleasure, forms knowledge, [and] produces discourse. It needs to be considered as a productive network which runs through the whole social body, much more than as a negative instance whose function is repression" (49). At the same time, the power that permeates everyday relationships can be connected to hegemonic purposes, defining dominant modes in the social order by excluding others and legitimizing a particular way of living.

In the context of development aid, power struggles are embedded within its discipline and institutions, often - despite liberating and participatory claims - with hegemonic intent (Hackner 2004). The developed world directs the evolution of the developing world, based on its own capitalism-driven success story (Moore and Schmitz 1995). Hegemony is used by the dominant social class as a means to organize its rule so it seems natural to its subjects (Moore and Schmitz 1995). These forces enact power not only through their practices but by promulgating ideas and preferences that define the world in Western terms via "captured social imaginaries and constructed identities" (Peet and Hartwick 1999, 146). Hegemony is not necessarily intentional. Rather, it is inherent in the relationships between the powerful and the powerless (Hackner 2004).

The prevailing ideas represented by a consensus of powerful thinkers of international development become the standard directives for development practitioners and the developing nations who have no choice but to adopt them (Hackner 2004). In other words, "Development is therefore at the same time rhetoric, official practice and political theory, while also serving as a framework for descriptions, on a global scale, of human misery and hope" (Rew 1997, 81). Major development decisions are frequently made because of ideologies and politics. Inadvisable actions are often taken: ones that do not solve the problem at hand or benefit recipients but do fit with the interests of those in power (Stiglitz 2002, x). Bradley (2006) points out:

Development practice is in reality a strategy for the maintenance of Western sovereignty through transforming the underdeveloped so as to fit them into a vision that reflects the way the dominant powers (West) would like the world to be.... The West requires proof that the developing country is competent in the task of changing itself in line with the Western model of modernization. (3)

It is now generally acknowledged in development literature that approaches based on modernization and dependency theories have suffered significantly from their top-down perspective. Bradley (2006) argues that development workers "operate within a world of mythical representation of other people because they are caught within a macro system of power that is not concerned with responding to real need" (xx). Aid recipients are not considered capable of decision making. Instead, dominant constructions of knowledge determine who is qualified to know and how much. The prevailing discourse is usually determined by a development "expert," the only one who has the wisdom 
to bring lasting change to communities (Bradley 2006). This mindset of professionals is especially problematic in one of the most sensitive areas of international development—gender and development.

\section{GAD and the Participatory Approach}

Gender and Development (GAD) perspective recognizes the family system in its diverse contexts and stresses the impact of structurally rooted inequalities. GAD acknowledges the social construction of different societies and particularly the predetermined roles and responsibilities assigned to women. Instead of focusing on isolated issues, GAD takes a holistic socio-cultural approach in its development programs (Bradley 2006).

GAD policy makers and practitioners use gender-disaggregated information to help design more effective programs. (Gender-disaggregated information considers each individual aid recipient as the unit of analysis, and can therefore articulate a precise picture of women's and men's roles both in a community and a country.) The GAD approach challenges the standard assumption in development practice that men alone support the family. It recognizes that women and men together support a family and therefore both roles need to be analyzed in their socio-cultural context (Thomas-Slayter, Esser, and Shields 1993).

The participatory approach has been widely used in development discourse ever since the WHO/UNICEF Alma Alta Declaration of 1978. Later development scholars have seen participation as a primary objective and method of development work. Nolan (2002) defines participation as "the involvement of different members of a society-groups and subgroups - in the decisions that will affect their lives, now and in the future." (21). This definition has become standard in the field of development aid.

Historically, the shift toward participatory development grew out of the failures of "externally imposed and expert-oriented" intervention efforts (Cooke and Kothari 2001, 5). By contrast, participatory development initiatives promote sustainable, gender-sensitive practices (Kamat 2002, 2). They seek to empower recipients who previously had "limited control or influence" (Cooke and Kothari 2001, 5). Recipients include people with less power and limited opportunities; that is, people marginalized by poverty or by gender (Banerjea 2007).

In recent decades, development agencies and donor organizations have increasingly recognized the importance of the participatory, grassroots approach. This growing emphasis has provided a new dimension to the field of international development-a critical shift away from top-down, professionally driven, and "rational-comprehensive styles of planning in favour of more bottom-up, community-driven and decentralised planning" (Beard and Cartmill 2007, 211). The shift is apparent in such development initiatives as gender equality, micro-financing, and women's education. It has been suggested that the move toward a community participation approach is playing a critical role in efficient, effective, and democratic planning and development initiatives.

Some development thinkers argue that participatory development has been presented as the gold standard in development practice, drawing as it does on modernist, Western assumptions that prioritize democracy, tolerance for difference, and representation for marginalized and elite groups alike (Bradley 2006). In theory, participatory development is supposed to give a voice to people whose society restricts their access to power (Morgan 2001). In practice, however, as indicated by many field studies, the results can be different: Participatory development is often used to satisfy the needs of donors, sustain hegemonic power relations, and secure the dominant discourse in the developing world (Desai 2002; Cornwall 2003; Bradley, 2006). For example, in the context of gender equality, Bradley (2006) argues that the "fictitious depiction" of rural Indian women by Western NGOs as passive and compliant does not help eradicate patriarchy (39). The result is the double repression of women: first by the patriarchy of their own conservative society, and second by "liberal Western feminists" who lead women's development NGOs in the developing world (Bradley 2006, 5).

Moreover, GAD practitioners argue that participation can become a "new tyranny" for development workers when it raises unrealistic expectations or overestimates the effectiveness of NGOs. Mikkelsen (2005) contends that participation is not, as many assume, the universal remedy, because there are limits to what interactive participation can achieve in equality and efficiency. There are significant socioeconomic inequalities and complex relations of power at the grassroots level in developing communities; these cannot be ignored.

In the development literature, it is often argued that the most effective way to achieve gender justice is to focus on structural and institutional transformation. This transformation would not only affect women's individual lives; it would also affect the socio-cultural institutions that enforce discrimination against women and guard against change. The GAD approach, however, presents a considerable challenge given that many of the values and norms limiting women's choices in Muslim societies are underwritten by Islamic assumptions and thus are assumed to be beyond 
discourse and argumentation (Hoodfar 2007; Kabeer 2001; Shaheed and Mumtaz 1993). Hoodfar (2007), who studied the leading role of Afghan women in the women's education movement in Iran, suggests that to remove the oppressive interpretation of Islamic values, Muslim women themselves would need to come forward and redefine those interpretations that have disempowered them. She contends that the key to gender-equality initiatives may remain within the paradigms of Islam - but with a progressive interpretation. Hoodfar argues:

Privileging and promoting more liberal interpretations of Islamic texts and re- examining what it means to be Muslim within an enabling environment can potentially empower women to make choices that can change gender relations, reshape social institutions and pave the way for a more equitable and democratic community and society.

Similarly, in the Pashtun region of Pakistan, Pakistani women who established women empowerment NGOs have been criticized for "taking on Western ideas unquestioningly....[They] have completely abandoned their own religious and cultural values, which in the view of many respondents were the real means of liberation" (Bano 2008, 108). When female NGO representatives approached women in rural Pakistan, the NGO workers were usually viewed as outsiders “... who cannot relate to [our] problems" (Bano 2008, 108).

There are, however, many examples of successful participatory development in the tribal areas bordering Pakistan and Afghanistan. When the communities were adequately involved and empowered, they welcomed development initiatives. When efforts were initiated with an open and honest mindset, the community embraced participation. For example, in Sawat and Malakand areas of northern Pakistan, the Taliban has burned dozens of girls' schools (Khan 2009). Nevertheless, a few miles away, the tribal communities have welcomed girls' education. Greg Mortenson has established more than seventy-eight schools in rural and often volatile regions of Pakistan and Afghanistan. These schools provide education to more than 28,000 children, including 18,000 girls, in an area where few educational opportunities existed before (Mortenson and Relin 2008). To obtain a school, villagers must provide the land and the labour, thus assuring a local "buy-in"; to date the Taliban has not bothered these schools. Notably, when an anti-American mob rampaged through Baharak, Afghanistan, attacking aid groups, they stopped at the school local people had just built with the help of an NGO. "This is our school," the mob leaders decided. They left it intact (Kristoff 2008, 13).

Moreover, among the estimated several thousand NGOs working in Pakistan and Afghanistan, an increasing number use religion as the core ideology guiding their "service to humanity." In the Pashtun areas, particularly the rural and tribal belt of Khyber Pakhtunkhwa Province (KPK), Islamic NGOs - with hundreds of committed volunteers who understand local values - have a grassroots presence and are perceived to be the most trusted and effective actors in any natural-disaster or humanitarian crisis. As Jamal (2013) suggests, instead of disengaging from the religious community, NGOs should establish strategic working relationships with Islamic organizations. Islamic NGOs' extensive networks represent a wealth of social, financial, cultural, and spiritual capital (Bergers 2003) that could be strategically used to further women's development and girls' education.

\section{Knowledge and Skills for NGO Workers in GAD}

The starting point of any development work is to listen to the voices of those whose understanding of life may be significantly different from one's own. It involves the skill of staying silent and the mindset of being open to differences of opinion (Bradley 2006). Ferguson (2003) defines reflexivity as "the ability to act in the world and to critically reflect on our actions and in ways that may reconstitute how we act and even reshape the very nature of identity itself" (199). Reflexivity offers a positive view of "others" (aid recipients) as members of the community who are capable of understanding and responding to their needs. Thus the relationship between NGO workers and aid recipients is founded on respect and willingness to appreciate their differences.

In the journey toward understanding the values of others, NGO workers first need to undergo personal exploration to understand their own ethnic self. This entails being aware of one's gender, race, and culture, and the potential effects of these characteristics on others (Herberg 1993). NGO workers need to develop self-reflexivity: distancing themselves from their own experiences and achieving a more objective view of their work so they can be influenced by the people they are attempting to help. Rogers and Stevens (1967) described the process beautifully: "When I accept myself as I am, then I change" (17). Self-reflexivity for the development worker thus includes looking at one's own "background, embodiment, personalities, and perspectives" and evaluating how these influence decisions about recipients (Fook 2002, 44).

Bradley (2006) suggests that the key to attaining reflexivity in development work is to separate self and culture. She 
writes: "Individuals must question which of their feelings, emotions and reactions are predetermined by the attitude of their own culture toward 'others' and which relate to who they innately are.... Warm acceptance of other beings as separate and different is important to achieve" (190). To understand others requires sensitivity toward others' culture and values that can only be achieved when workers realize "who they innately are" and piece together their own values, emotions, and feelings (Bradley 2006).

Bhawuk and Brislin (1992) note key predictors of success:

To be effective in another culture, people must be interested in other cultures, be sensitive enough to notice cultural differences, and then also be willing to modify their behaviour as an indication of respect for the people of other cultures. A reasonable term that summarizes these qualities of people is intercultural sensitivity. (416)

In practice, such intercultural sensitivity seeks to understand and respond to criticisms of NGO representatives as overly Westernized and unwilling to adapt to the cultures of local communities. This involves making room for greater interaction with those in need and ultimately furthers the usefulness of the project.

To assess the effectiveness of Canadian professionals in developing countries, the Canadian International Development Agency (CIDA) conducted a number of studies. In one, twenty-two professionals were assessed prior to leaving for an international project and again after one year of field work. It was found that effective development work can be predicted by the following seven skills: empathy, respect, role behaviour, nonjudgmentalness, openness, tolerance for ambiguity, and interaction management (Kealey 2001). Subsequent CIDA studies affirmed that intercultural interaction and adaptation to the host culture are key competencies for overseas projects (Kealey 2001). Nevertheless, despite knowing that being involved in the host's culture is critically important for a development professional, many workers acknowledged that they had "little social contact with the people from the host country" (11). Several studies found working in a different culture to be a demanding job that requires not only commitment but special skills and attitudes. A significant number of development professionals "gave up the challenge and retreated into the expatriate ghetto" (Kealey 2001, 87).

In this context, Bradley (2006) emphasizes the importance of hybridity: the natural process of identification and integration between supposedly bounded cultures. Hybridity requires an open and honest attitude blended with appropriate training programs, all with the objective of gaining the trust of the community by understanding and respecting the people's cultural values and traditions.

While development organizations continue to grow and employ notions of "participatory development" and "partnership," studies indicate that NGOs often fail to effectively involve the community in their programs (Bano 2008). Fowler (2002) argues that NGOs "in many developing countries, are the object of government mistrust and public suspicion" (29). In China and Vietnam, due to poor connections with local peoples, NGOs face serious issues of legitimacy and trust (Bano 2008). In most Muslim countries, GAD initiatives have been viewed as a means by which the West seeks to wipe out the values and beliefs of Muslim societies. Some scholars portray the GAD approach as the "battlefield" on which the conflict between Islam and the West is played out (Adamu 1999). After conducting a countrywide survey on the perception of NGOs in Pakistan, Bano (2008) found that even among educated professionals in cities, NGOs elicited jokes and derogatory comments:

- "An NGO visited today; it was wearing high heels and a short shirt" (99).

- "There is a lot of money in poverty." (95)

- "One can only look down on the poor from these NGOs' four-wheel drives; one cannot feel much for them." (95)

- NGOs represent "marble coffee-table human rights." (95)

It is tempting to ask why NGOs are perceived so negatively. Alternatively, we may approach a solution from a different direction: by examining successful experiences and noting their common features.

As discussed above, the positive experience of some NGOs tells us that when efforts are made to involve marginal local voices, NGOs are trusted and respected by the community. The literature on development suggests that the following features can help NGOs establish trust in developing countries.

Display of Respect: The community perceives NGOs to be representative of their voice and respectful of their values and traditions. This is most visible in GAD programs. In practical terms, it requires an individual display of deep respect for the worth of others as persons of high potential and the ability to respond to others and their customs in a descriptive, nonjudgmental manner (Bano 2005).

Acknowledging Others: It is important to establish a reciprocal relationship in which both the development 
professional and the recipient reflect that they have learned from each other (Irigaray 2000).

Listening: In responding to community need, first the NGO worker should have both a passion and the skills to listen to the experiences of the local community. But the key is to listen without any disparaging, value-laden interpretation. Remember: "When I accept who I am, then I change" (Rogers and Stevens 1967).

Humanitarian Consciousness: Development workers should value human dignity and the common spirit of humanity. They need to believe that human beings can ultimately find solutions to seemingly insoluble problems. They should have an awareness of perspectives that underlie stereotypes of dependency, growth, and benefit (Smyser 2003).

Long-term Commitment: Communities are not static. They function and are continuously affected by internal and external political, socio-cultural, and economic conditions. The development worker should have a long-term commitment to the changing needs of the community (Bradley 2006). Regular visits would help in establishing the image of a long-term commitment. During my development work with Afghan refugees, I heard it many times: "They [Western NGOs] come with a political agenda; when political goals are achieved they forget that there is even a country named Afghanistan."

Making GAD an Inclusive Approach: Despite its holistic definition, the word gender remains focused on women's interventions. While women remain the most marginalized and oppressed group, improving the socioeconomic condition of women involves the participation of both men and women (Smith 1990).

When combined, these elements promote a positive environment in which to engage in development work. They highlight the importance of valuing the contribution, culture, and ideas of local communities without imposing Western frames or purposes on them. Instead, they incorporate the input of everyone involved in order to build a successful outcome. Unless efforts are made to constructively engage marginalized and disadvantaged voices of both men and women, participatory development will remain a superficial term with no value at ground level.

\section{Engaging Men in GAD}

As argued above, GAD and participatory approaches would benefit from expanding women's development initiatives to include programs for men and women simultaneously. In many countries, both developing and developed, groups of men have emerged who, after being exposed to new modes of education and development, have begun to ponder the desperate situation of women in their communities. These groups share the fundamental principle that men must take responsibility for ending their aggressive attitude toward women's active participation in society.

There are historical precedents of men's active participation in gender justice. As noted by Metcalf (2002), in the nineteenth century men were key actors in the struggle for women's development. Esplen (2006) points out that small numbers of men and boys in developing countries are changing their attitudes and behaviours toward women; they reject fixed gender division and are open to "gender equitable" alternatives; they speak out against gender-based discrimination. However, the challenge is to develop policies and programs that effectively use these positive attitudes and behaviours to achieve gender equality. Esplen writes:

Initiatives need to engage men as allies, using positive and relevant messages, which also address their specific concerns. By highlighting the costs of gender inequality, as well as the benefits of gender equality - both for men as individuals, and as members of families and communities-programmes can support men to reflect on, and ultimately resist, harmful constructions of masculinity. (4)

Several studies suggest that when fathers are positively engaged in the lives of their children, they are more likely to be helpful to their partners and to be involved in school activities (Morrell 2005; Esplen 2006). As Esplen (2006) writes, "When fatherhood is privileged as a central aspect of masculinity, everybody benefits" (10). In the context of gender equality it is important to listen to the voices of fathers, understand their views and concerns, and actively engage them in women's issues by explaining to them the benefits of participating in their daughters' issues as fathers (Barker 2005).

The goal of gender equality requires not only a change in mindset, attitudes, and behaviours, but a significant shift in the existing power relations between women and men (Ruxton 2004; Esplen 2006). A shift is possible, however, only when both women and men are engaged in overcoming barriers. Ruxton (2004) argues that unless there is a significant change in men's practices and attitudes, the struggle for gender equality will be an uphill fight. For these reasons, we need to understand more deeply the perspective of men in developing countries. To date, however, there 
is a scarcity of research on men, especially in Islamic contexts (Esplen 2006). Studies of gender equality in most Muslim societies primarily discusses issues of hijab and the oppression of women. Studies of men's roles and participation in GAD discourse are rare in the development literature (Esplen 2006).

In the rural Pashtun areas of Pakistan and Afghanistan, where a significant majority of women are living under strict tribal codes, men's participation in women's development and education is critically important. In a recent study among Pashtun tribes of northwest Pakistan, Jamal (2013) concluded that constructively engaging men, particularly community elders and Imams (religious leaders), is a key to opening doors to girls' education. Strong adherence to cultural norms and a well-established patriarchal system may restrict women's opportunities for development until men are convinced that it is necessary to change.

\section{Conclusion}

While the tensions discussed at the start of this article continue to be sources of challenges in GAD programs, they also bring many opportunities. Besides embedded assumptions and a number of institutional and socio-cultural obstacles, participatory approaches in GAD programs have much to offer. Participatory development programs could make a significant difference if they are used in conjunction with a self-reflexive, culturally sensitive, honest, and open state of mind. As Cornwall (2003) points out, instead of the "add-women-and-stir" approach to addressing gender, a combination of policies and implementation strategies that seriously consider the power effects of difference is needed. This would require joining advocacy with a willingness to give space to those who are least heard, thereby enabling people to recognize and use their abilities, insights, and freedom.

In the area of gender and development, a participatory approach can potentially play a critical role, but it requires the incorporation of "new alliances out of old divisions" (Cornwall 2003, 1). Specifically, it requires men. Men's engagement in gender matters is both a political issue and an effective form of social justice, as it would engage the members of a privileged group in order to challenge that same privilege (Flood 2001). There are always, of course, risks in taking on such sensitive projects in patriarchal societies racked with wars and internal conflicts. Nevertheless, men's participation would significantly enrich development work, bringing us ever closer to the elusive goal of gender justice.

\section{References}

Adamu, F. (1999). A Double-edged Sword: Challenging Women's Oppression within Muslim Society in Northern Nigeria. Gender and Development: Gender, Religion and Spirituality, 7(1), 56-61. http://dx.doi.org/10.1080/741922934

Baaz, M. E. (2005). The Paternalism of Partnership: A Postcolonial Reading of Identity in Development Aid. London: Zed Books.

Banerjea, N. (2007). Poor Women's Mobilization and Participatory Development: An Ethnography of Volunteering Practices in a Kolkata Slum. PhD diss., State University of New York at Buffalo.

Bano, M. (2005). Self-interest, Rationality, and Cooperative Behaviour: Aid and Problems of Cooperation within Voluntary Groups in Pakistan. D. Phil. thesis, University of Oxford.

Bano, M. (2008). Dangerous Correlations: Aid's Impact on NGOs' Performance and Ability to Mobilize Members in Pakistan. World Development, 36(11), 2297-2313. http://dx.doi.org/10.1016/j.worlddev.2007.11.001

Barker, G. (2005). Dying to be Men: Youth, Masculinity and Social Exclusion. London: Routledge.

Beard, V. A., \& Cartmill, R. S. (2007). Gender, Collective Action and Participatory Development in Indonesia. International Development Planning Review, 29(2), 185-213. http://dx.doi.org/10.3828/idpr.29.2.3

Bergers, J. (2003). Religious Nongovernmental Organizations: An Exploratory Analysis. Voluntas: International Journal of Voluntary and Nonprofit Organizations, 14(1), 15-39. http://dx.doi.org/10.1023/A:1022988804887

Bhawuk, A., \& W. Brislin. (1992). The Measurement of Intercultural Sensitivity: Using the Concepts of Individualism and Collectivism. International Journal of Intercultural Relations, 16(4), 413-436. http://dx.doi.org/10.1016/0147-1767(92)90031-O

Bradley, T. (2006). Challenging the NGOs: Women, Religion and Western Dialogues in India. London: Tauris Academic Studies. 
Cooke, B., \& U. Kothari. (2001). Participation: The New Tyranny? London: Zed Books.

Cornwall, A. (2003). Whose Voices? Whose Choices? Reflections on Gender and Participatory Development. World Development, 31(8), 1325-1342. http://dx.doi.org/10.1016/S0305-750X(03)00086-X

Desai, U. (2002). Environmental Politics and Policy in Industrialized Countries. Cambridge, MA: MIT Press.

Esplen, E. (2006). Engaging Men in Gender Equality: Positive Strategies and Approaches. Bibliography No. 15, Institute of Development Studies, University of Sussex.

Ferguson, H. (2003). Welfare, Social Exclusion and Reflexivity: The Case of Child and Woman Protection." Journal of Social Policy, 32(2), 199-216. http://dx.doi.org/10.1017/S0047279402006967

Flood, M. (2001). Men's Collective Anti-violence Activism and the Struggle for Gender Justice. Development, 44(3), 42-47. http://dx.doi.org/10.1057/palgrave.development.1110260

Fook, J. (2002). Social Work: Critical Theory and Practice. London: Sage.

Foucault, M. (1980). Power/Knowledge: Selected Interviews and Other Writings 1972-1977. New York: Vintage.

Fowler, A. (2002). The Virtuous Spiral: A Guide to Sustainability for Non-governmental Organisations in International Development. London: Earthscan.

Hackner, M. (2004). Shaping International Development Discourse: The Embeddedness of Economic Theory and Policy Reform. MA thesis, Georgetown University.

Henderson, S. (2002). Selling Civil Society: Western Aid and the Nongovernmental Organization Sector in Russia. Comparative Political Studies, 35(2), 139-67. http://dx.doi.org/10.1177/0010414002035002001

Herberg, D. C. (1993). Frameworks for Cultural and Racial Diversity. Toronto: Canadian Scholars' Press.

Hoodfar, H. (2007). Women, Religion and the 'Afghan Education Movement' in Iran. Journal of Development Studies, 43(2), 265-93. http://dx.doi.org/10.1080/00220380601125115

Irigaray, L. (2000). Democracy Begins Between Two. London: Athlone Press.

Jafar, A. (2007). Engaging Fundamentalism: The Case of Women's NGOs in Pakistan. Social Problems, 54(3), 256-73. http://dx.doi.org/10.1525/sp.2007.54.3.256

Jamal, A. (2013). Engaging Men for Gender Justice: Overcoming Barriers to Girls' Education Among Pashtun Tribes Of Northwest Pakistan. Unpublished PhD diss., Faculty of Social Work, University of Calgary, Alberta, Canada.

Kabeer, N. (2001). Ideas, Economics and 'the Sociology of Supply': Explanations for Fertility Decline in Bangladesh. Journal of Development Studies, 38(1), 29-70. http://dx.doi.org/10.1080/00220380412331322181

Kamat, S. (2002). Development hegemony: NGOs and the state in India. New York: Oxford University Press.

Kealey, D. (2001). Cross-cultural Effectiveness: A Study of Canadian Technical Advisors Overseas (2nd ed.). Hull, QC: Dept. of Foreign Affairs \& International Trade, Canadian Foreign Service Institute, Centre for Intercultural Learning.

Khan, H. (2009). Militants Blow Up Five More Schools. Daily Dawn, Pakistan. Retrieved 29 January 2009 from http://www.dawn.com/2009/01/20/top7.htm

Kristoff, N. (2008). It Takes a School, Not Missiles. New York Times, 13 July. Retrieved 13 November 2013 from http://www.nytimes.com/2008/07/13/opinion/13kristof.html

Laclau, E., \& C. Mouffe. (2001). Hegemony and Socialist Strategy: Towards a Radical Democratic Politics (2nd ed.). London: Verso.

Laumann, L. C. (2000). Teaching Gender: Pakistani Nongovernmental Organizations and Their Gender Pedagogies. PhD diss., University of California, Los Angeles.

Metcalf, B. D. (2002). Islamic Revival in British India: Deoband, 1860-1900. New Delhi: Oxford University Press.

Mikkelsen, B. (2005). Methods for Development Work and Research: A New Guide for Practitioners (2nd ed.). Thousand Oaks, CA: Sage.

Moore, D. B., \& G. Schmitz. (1995). Debating Development Discourse: Institutional and Popular Perspectives. New York: St. Martin's Press. 
Morgan, L. (2001). Community Participation in Health: Perpetual Allure, Persistent Challenge. Health Policy and Planning, 16(3), 221-30. http://dx.doi.org/10.1093/heapol/16.3.221

Morrell, R. (2005). Youth, Fathers and Masculinity in South Africa Today. Agenda: Special Focus, 84-87.

Mortenson, G., \& D. Relin. (2008). Three Cups of Tea: One Man's Mission to Promote Peace - One School at a Time. New York: Penguin Books.

Naviwala, N. (2010). Harnessing Local Capacity: US Assistance and NGOs in Pakistan, Harvard Kennedy School Policy Exercise USAID Afghanistan-Pakistan Task Force. Retrieved 14 November 2013 from http://www.hks.harvard.edu/cchrp/sbhrap/forum/article_0003/HarnessingLocalCapacity.pdf

Nolan, R. W. (2002). Development Anthropology: Encounters in the Real World. Boulder, CO: Westview Press.

Nuccio, K. E., \& R. G. Sands. (1992). Using Postmodern Feminist Theory to Deconstruct "Phallacies" of Poverty. Affilia: Journal of Women \& Social Work, 7(4), 26-48. http://dx.doi.org/10.1177/088610999200700403

Peet, R., \& E. R. Hartwick. (1999). Theories of Development. New York: Guilford Press.

Rew, A. (1997). The Donors' Discourse: Official Social Development Knowledge in the 1980s. In Discourses of development, edited by R. Grillo and R. Stirrat. Oxford: Berg.

Rogers, C. R., \& B. Stevens. (1967). Person to Person: The Problem of Being Human: A New Trend in Psychology. Walnut Creek, CA: Real People Press.

Ruxton, S. (2004). Gender Equality and Men: Learning from Practice. Oxford: Oxfam.

Shaheed, F., \& K. Mumtaz. (1993). Women's Education in Pakistan. In The Politics of Women's Education: Perspectives from Asia, Africa, and Latin America, edited by J. K. Conway and S. C. Bourque. Ann Arbor: University of Michigan Press.

Shehabuddin, R. E. (2000). Encounters with the State: Gender and Islam in Rural Bangladesh. PhD diss., Princeton University.

Smith, D. (1990). The Conceptual Practices of Power. Toronto: University of Toronto Press.

Smyser, W. (2003). The Humanitarian Conscience (1st ed.). New York: Palgrave Macmillan.

Stiglitz, J. (2002). Globalization and Its Discontents. New York: Norton.

Thomas-Slayter, B., A. L. Esser, \& M. D. Shields. (1993). Tools of Gender Analysis: A Guide to Field Methods for Bringing Gender into Sustainable Resource Management. Clark University Press, MA.

Thomsson, D. (2006). Solidarity Not Charity: Discourse of Power in Partnership and Development Aid. Sweden: Linkoping University.

Van den Boom, D. (1999). Individual intercultural communicative competence. In Labour-market integration of migrants and refugees advice and guidance. Retrieved 14 November 2013 from http://www.agef-saar.de/AHOI/Lima/StartLima.htm

Wendt, S., \& J. Boylan. (2008). Feminist Social Work Research Engaging with Post Structural ideas. International Social Work, 51(5), 599-609. http://dx.doi.org/10.1177/0020872808093339 